\title{
dspace.vutbr.cz
}

\section{Integrated diagnostic system for winding fault detection of the three-phase PMSM}

\author{
OTAVA, L.; BUCHTA, L.
}

Proceedings of the 2020 12th International Congress on Ultra Modern Telecommunications and Control Systems and Workshops (ICUMT), pp. 33-40

elSBN: 978-1-7281-9281-9

ISSN: 2157-023X

DOI: https://doi.org/10.1109/ICUMT51630.2020.9222438

Accepted manuscript

(C2020 IEEE. Personal use of this material is permitted. Permission from IEEE must be obtained for all other uses, in any current or future media, including reprinting/republishing this material for advertising or promotional purposes, creating new collective works, for resale or redistribution to servers or lists, or reuse of any copyrighted component of this work in other works. OTAVA, L.; BUCHTA, L., "Integrated diagnostic system for winding fault detection of the three-phase PMSM", Integrated diagnostic system for winding fault detection of the three-phase PMSM, 2020. DOI: 10.1109/ICUMT51630.2020.922243. Final version is available at 


\title{
Integrated diagnostic system for winding fault detection of the three-phase PMSM
}

\author{
Lukáš Otava \\ CEITEC, Brno University of Technology \\ Brno, Czech Republic \\ Lukas.Otava@ceitec.vutbr.cz, ORCID 0000-0003-2442-816X
}

\author{
Luděk Buchta \\ CEITEC, Brno University of Technology \\ Brno, Czech Republic \\ Ludek.Buchta@ceitec.vutbr.cz
}

\begin{abstract}
This paper deals with the detection of the winding faults of the three-phase PMSM. The algorithm based on the three-phase model of the winding and the extended Kalman filter is used for inter-turn short detection. Additionally, the functionality of the sensors used for the detection algorithms is verified. The decision system is in charge of the diagnosis of the fault (winding/sensors). All the presented algorithms were implemented in Simulink and tested on data measured on a real inverter with the motor connected to the dynamometer. Algorithms were also tested on a microcontroller.

Index Terms-Synchronous motor, Diagnostics, Faults, Estimation technique, Microcontrollers;
\end{abstract}

\section{INTRODUCTION}

PMSM drives are very popular due to their high precision, low inertia and the power-to-weight density, even in very reliable applications. However, motor and sensor faults should be considered in such drives running different operating conditions. The second most frequent motor fault is the stator winding fault [1]. Stator winding usually degrades rapidly due to a winding fault. Thus it is very important to detect a stator winding fault as soon as possible. This paper focuses especially on inter-turn short fault using extended Kalman filter (EKF) estimator of the stator winding quantities.

There are paper dealing with the interturn short winding fault [2] and [3]. There are also particular applications of the EKF for parameter estimation and fault detection (FD) [4], [5], [6]. Most of the EKF fault detection methods for PMSMs use two-phase models (the $\alpha \beta$ or $d q$ reference frame). The presented implementation benefits from the three-phase model, because it can easily identify faulty phase winding and the algorithm is robust to motor parameters variation.

Sensor functionality of PMSM drive is discussed by autors of [7] and [8], but detection of the sensor functionality with relation to the interturn fault has not been presented yet.

Past research was focused on the stator winding fault detection method based on the estimation of three stator resistances. The algorithm was described and verified on microcontroller, presented in [9]. This paper extends the previously developed

This article is part of the 1000kmPLUS project that has received funding from the European Union's Horizon 2020 research and innovation programme under grant agreement No 824262 .

This research has been financially supported also by the Ministry of Education, Youth and Sports of the Czech republic under the project CEITEC 2020 (LQ1601).

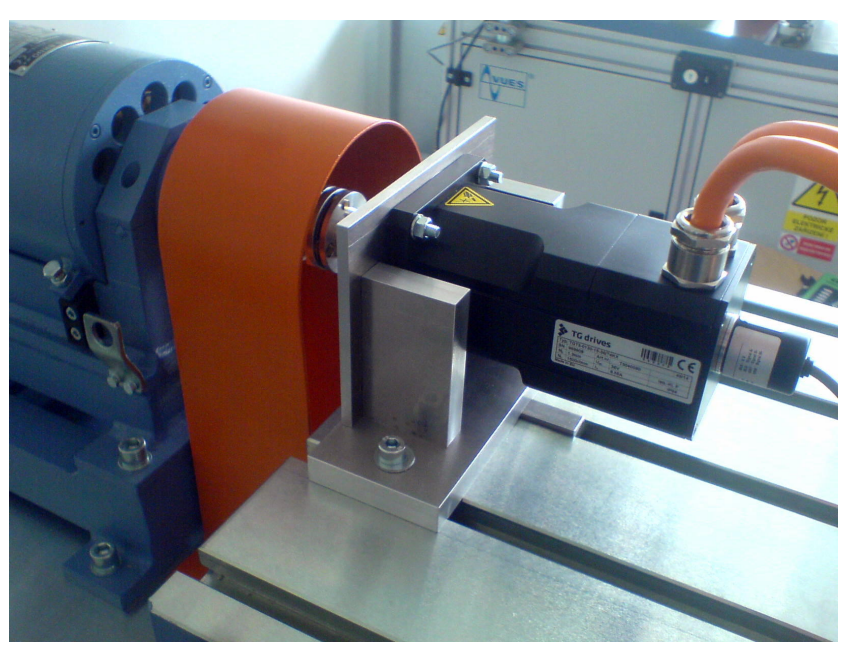

Fig. 1. Motor connected to a dynamometer

algorithm to estimation of the stator resistance and backelectromotive force (BEMF) voltage scale coefficients $C_{\mathrm{abc}}$.

Apart from the winding fault detection, the paper describes the integration of the algorithms for the detection of sensor functionality. These sensors are needed for field-oriented control loop and winding diagnostic algorithms. This is done only with a limited number of additional sensors, rotor position sensor (incremental encoder), three-phase current sensors, DCbus voltage and DC-bus current sensor.

The TG Drives TGT3 low voltage PMSM motor with nominal power $200 \mathrm{~W}$ is used in experiments (Fig. 1). The machine is slightly modified for interturn phase fault emulation (two winding steps, see Fig. 9). The fault detection algorithms are tested by emulated faults listed in Table I.

TABLE I

LIST OF FAULTS EMULATED DURING EXPERIMENTS

\begin{tabular}{|l|l|}
\hline Hardware emulated (Fig. 9) & Software emulated \\
\hline \hline $\begin{array}{l}\text { Inter-turn short fault in one } \\
\text { phase } f_{\text {its }}\end{array}$ & $\begin{array}{l}\text { Phase current sensor offset } \\
\text { fault } f_{\text {i_sensor_offset }} \text { and gain er- } \\
\text { ror fault } f_{\text {i_sensor_gain }}\end{array}$ \\
\hline Open-phase fault $f_{\text {op }}$ & Position sensor offset $f_{\text {position }}$ \\
\hline $\begin{array}{l}\text { Winding star-point to ground } \\
\text { short } f_{\text {sn }}\end{array}$ & DC-bus sensor gain error $f_{\text {u_DC }}$ \\
\hline
\end{tabular}




\section{WINDING FAULT DETECTION}

Winding fault detection is based on a three-phase stator winding model and EKF estimator. The stator winding of nonsalient PMSM motor can be described by (1) [10]

$$
\frac{\mathrm{d} \mathbf{i}_{\mathrm{abc}}}{\mathrm{d} t}=\mathbf{L}^{-1}\left(\mathbf{u}_{\mathrm{abc}}-\mathbf{R}_{\mathrm{abc}} \mathbf{i}_{\mathrm{abc}}-\mathbf{e}_{\mathrm{abc}}\right) .
$$

Where $\mathbf{i}_{\mathrm{abc}}=\left[\begin{array}{ccc}i_{\mathrm{a}} & i_{\mathrm{b}} & i_{\mathrm{c}}\end{array}\right]^{\top}$ is stator current vector and $\mathbf{u}_{\mathrm{abc}}=\left[\begin{array}{lll}u_{\mathrm{a}} & u_{\mathrm{b}} & u_{\mathrm{c}}\end{array}\right]^{\top}$ is the stator voltage vector.

Inductance matrix is

$$
\mathbf{L}=\left[\begin{array}{ccc}
L_{\mathrm{ls}}+L_{\mathrm{m}} & -\frac{1}{2} L_{\mathrm{m}} & -\frac{1}{2} L_{\mathrm{m}} \\
-\frac{1}{2} L_{\mathrm{m}} & L_{\mathrm{ls}}+L_{\mathrm{m}} & -\frac{1}{2} L_{\mathrm{m}} \\
-\frac{1}{2} L_{\mathrm{m}} & -\frac{1}{2} L_{\mathrm{m}} & L_{\mathrm{ls}}+L_{\mathrm{m}}
\end{array}\right]
$$

Items of the inductance matrix are $L_{\mathrm{ls}}=L_{0}$ and $L_{\mathrm{m}}=$ $\frac{1}{3}\left(L_{\mathrm{d}}+L_{\mathrm{q}}-2 L_{0}\right)[11]$.

For stator winding fault detection, the BEMF voltage vector $\mathbf{e}_{\mathrm{abc}}$ and stator resistance matrix $\mathbf{R}_{\mathrm{abc}}$ were extended by $C_{\mathrm{a}}$, $C_{\mathrm{b}}$ and $C_{\mathrm{c}}$ parameters representing unbalance of the winding due to the interturn short fault

$$
\begin{aligned}
& \mathbf{e}_{\mathrm{abc}}=-\omega \Psi_{\mathrm{m}}\left[\begin{array}{c}
C_{\mathrm{a}} \sin \theta \\
C_{\mathrm{b}} \sin \left(\theta-\frac{2 \pi}{3}\right) \\
C_{\mathrm{c}} \sin \left(\theta+\frac{2 \pi}{3}\right)
\end{array}\right], \\
& \mathbf{R}_{\mathrm{abc}}=\left[\begin{array}{ccc}
C_{\mathrm{a}} R_{\mathrm{S}} & 0 & 0 \\
0 & C_{\mathrm{b}} R_{\mathrm{S}} & 0 \\
0 & 0 & C_{\mathrm{c}} R_{\mathrm{S}}
\end{array}\right] .
\end{aligned}
$$

Where $\omega$ is electrical rotor velocity, $\Psi_{\mathrm{m}}$ is the motor BEMF constant, and $R_{\mathrm{S}}$ is stator phase resistance.

For the parameter estimation, the stator system (1) was augmented with the estimated parameters as constant states

$$
\frac{\mathrm{d}}{\mathrm{d} t} \mathbf{C}_{\mathrm{abc}}=\frac{\mathrm{d}}{\mathrm{d} t}\left[\begin{array}{c}
C_{\mathrm{a}} \\
C_{\mathrm{b}} \\
C_{\mathrm{c}}
\end{array}\right]=\left[\begin{array}{l}
0 \\
0 \\
0
\end{array}\right] .
$$

The state vector of the system is

$$
\hat{\mathbf{x}}=\left[\begin{array}{llllll}
i_{\mathrm{a}} & i_{\mathrm{b}} & i_{\mathrm{c}} & C_{\mathrm{a}} & C_{\mathrm{b}} & C_{\mathrm{c}}
\end{array}\right]^{\top} .
$$

The inputs of the estimator are the rotor velocity $\omega$, rotor angle $\theta$, and phase voltages $\mathbf{u}_{\mathrm{abc}}$. The phase voltages are computed from the current controller outputs. The stator currents $i_{a b c}$ are taken as the system outputs measurements. The EKF input and measurement vectors are

$$
\mathbf{u}=\left[\begin{array}{lllll}
u_{\mathrm{a}} & u_{\mathrm{b}} & u_{\mathrm{c}} & \omega & \theta
\end{array}\right]^{\top}, \quad \mathbf{z}=\left[\begin{array}{lll}
i_{\mathrm{a}} & i_{\mathrm{b}} & i_{\mathrm{c}}
\end{array}\right]^{\top} .
$$

\section{A. Extended Kalman Filter}

The EKF algorithm can be generally divided into two steps [12]. Prediction step estimates state from past values according to the following equation

$$
\hat{\mathbf{x}}_{k}^{-}=\mathbf{f}\left(\hat{\mathbf{x}}_{k-1}, \mathbf{u}_{k}\right) .
$$

The continuous-time model was discretized by Euler method.

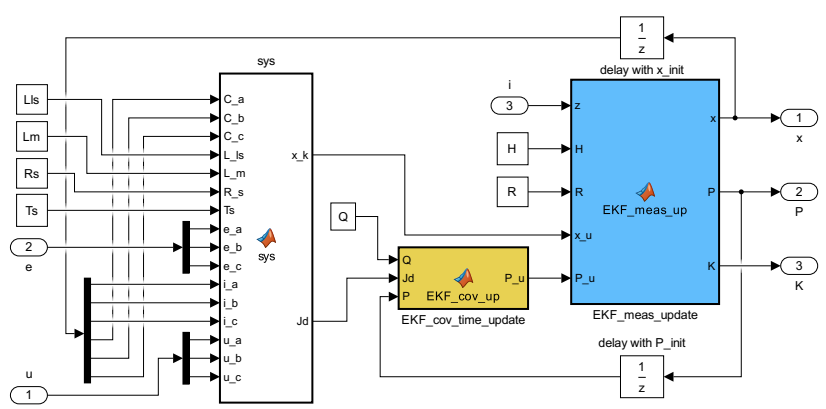

Fig. 2. Simulink implementation of the $C_{\mathrm{abc}}$ EKF estimator

Covariance matrix prediction $\mathbf{P}_{k}^{-}$is computed according to the equation

$$
\mathbf{P}_{k}^{-}=\mathbf{F}_{k} \mathbf{P}_{k-1} \mathbf{F}_{k}^{\top}+\mathbf{Q},
$$

where $\mathbf{Q}$ is a process noise covariance matrix and $\mathbf{F}$ is a Jacobi matrix representing the linearization of the system with the first element of the Taylor series.

Correction step contains Kalman gain $\mathbf{K}_{k}$ computation

$$
\mathbf{K}_{k}=\mathbf{P}_{k}^{-} \mathbf{H}_{k}^{\top}\left(\mathbf{H}_{k} \mathbf{P}_{k}^{-} \mathbf{H}_{k}^{\top}+\mathbf{R}\right)^{-1}
$$

where $\mathbf{R}$ is a measurement noise covariance matrix, $\mathbf{H}$ is a Jacobi matrix, which represents the linearization of the output function.

Then, the states are corrected according to measurement residuals and Kalman gain

$$
\hat{\mathbf{x}}_{k}=\hat{\mathbf{x}}_{k}^{-}+\mathbf{K}_{k}\left(\mathbf{z}_{k}-\mathbf{g}\left(\hat{\mathbf{x}}_{k}^{-}\right)\right) .
$$

The last step of EKF algorithm is a covariance matrix update

$$
\mathbf{P}_{k}=\left(\mathbf{I}-\mathbf{K}_{k} \mathbf{H}_{k}\right) \mathbf{P}_{k}^{-} .
$$

The setting of the measurement noise covariance matrix $\mathbf{Q}$ was performed according to the current measurement noise

$$
\mathbf{Q}=\operatorname{diag}\left(\begin{array}{lll}
0.003 & 0.003 & 0.003
\end{array}\right) \text {. }
$$

The process noise covariance matrix $\mathbf{R}$ was selected experimentally to get a smooth update of estimated parameters

$$
\mathbf{R}=\operatorname{diag}\left(\begin{array}{llllll}
10^{-4} & 10^{-4} & 10^{-4} & 10^{-9} & 10^{-9} & 10^{-9}
\end{array}\right) .
$$

Initial value of the covariance $\mathbf{P}(0)$ and state $\hat{\mathbf{x}}(0)$ were selected as

$$
\begin{aligned}
\mathbf{P}(0) & =\operatorname{diag}\left(\begin{array}{lllllll}
0.5 & 0.5 & 0.5 & 0.5 & 0.5 & 0.5
\end{array}\right), \\
\hat{\mathbf{x}}(0) & =\left[\begin{array}{llllll}
0 & 0 & 0 & 1 & 1 & 1
\end{array}\right]^{\top} .
\end{aligned}
$$

The fault indicator $\delta_{\mathrm{mm}}$ is defined as the difference between maximum and minimum of $\mathbf{C}_{\mathrm{abc}}$. The Simulink implementation of the $\mathbf{C}_{\mathrm{abc}}$ estimation is in Fig. 2. The performance of the algorithm on real data is discussed in V-A. 


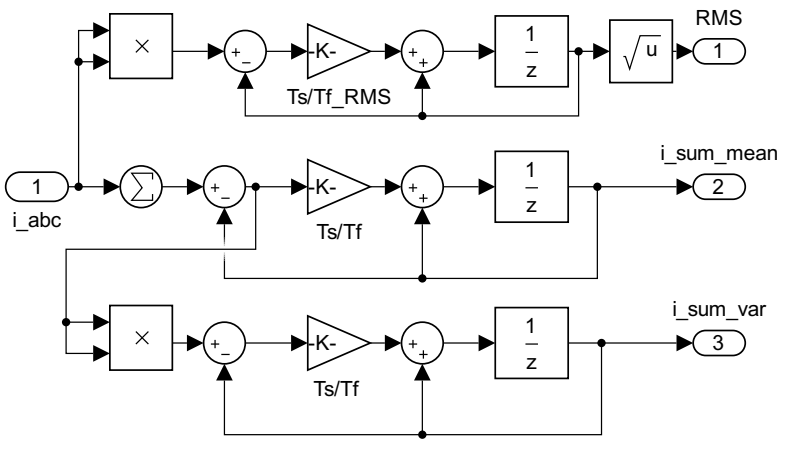

Fig. 3. Simulink implementation of the block for estimation of the RMS, mean and variance

\section{SEnSORS FAult DETECTION}

The field-oriented motor control loop and the winding fault algorithms rely on measurements of PMSM motor quantities. Therefore it is needed to evaluate the plausibility of sensor measurement.

A general sensor measurement chain consists of power supply, sensor itself, connections, signal conditioning, conversion, data transfer, and $100 \%$ reliability is not achievable. A common solution to evaluate sensor functionality is to use additional redundant sensors and crosscheck output of both sensors. But this is not usually possible due to the increase in cost. Therefore, there is an inclination to use estimators as virtual sensors in specific positions. Uncertainties in the system make it impossible to use estimators instead of all sensors. There is a trade-off between used sensors and detectable faults due to the limited observability.

\section{A. Phase currents FD}

The stator phase current measurement is crucial for the whole system. The FOC requires only two-phase currents to operate because the third can be computed. Therefore, the use of three-phase current sensors allows us to partially check the functionality of the phase current measurement. Current leakage from phase legs due to possible short circuits to the motor case should be also considered to properly detect phase current sensor fault.

Phase currents sensor FD is based on processing of $i_{\text {sum }}$

$$
i_{\mathrm{a}}+i_{\mathrm{b}}+i_{\mathrm{c}}=i_{\text {sum }} .
$$

According to Kirchhoff's current law, the value of the $i_{\text {sum }}$ should be zero. But due to current sensors faults or current leakage from inverter legs, the $i_{\text {sum }}$ becomes a nonzero or periodic signal. Estimating the mean and variance of the $i_{\text {sum }}$ enables us to decide which fault is present. The structure of the algorithm estimating the mean and the variance of the $i_{\text {sum }}$ with two low-pass filters is in Fig. 3. The variance of the $i_{\text {sum }}$ is used for current sensor gain fault $f_{i_{\text {_ssum_var }}}$ detection and the absolute value of the $i_{\text {sum }}$ mean is used for current sensor offset fault $f_{\text {i_sum_mean }}$ detection.

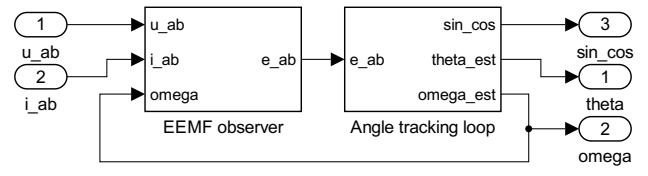

Fig. 4. Rotor position estimation algorithm overview

The current sensor offset fault and the winding short to motor case fault are distinguished using additional DC-bus current sensor $i_{\mathrm{DC}}$ and estimation of the inverter DC current consumption $i_{\mathrm{DC} \text { est }}$. The DC bus current can be estimated using stator current, stator voltage and DC bus voltage

$$
i_{\text {DC_est }}=\frac{\mathbf{i}_{\mathrm{abc}}^{\top} \mathbf{u}_{\mathrm{abc}}}{u_{\mathrm{DC}}} k_{\text {gain }}+k_{\text {bias }} .
$$

Where $\mathbf{i}_{\mathrm{abc}}$ is stator current vector, $\mathbf{u}_{\mathrm{abc}}$ is stator voltage vector and $u_{\mathrm{DC}}$ is DC bus voltage. Constant $k_{\text {gain }}$ compensates gain error and $k_{\text {bias }}$ compensates bias. These constants compensate measurement sensors error and voltage inverter nonlinear behavior. In case a more nonlinear voltage inverter is used, more complex compensation of the DC bus current estimation is needed.

Using fminsearch, the constants $k_{\text {gain }}=0.97$ and $k_{\text {bias }}=$ 0.057 were found for particular inverter system. The measured $i_{\mathrm{DC}}$ is compared with the estimated one $i_{\mathrm{DC} \_ \text {est }}$ to detect current leakage (the winding short to motor case) fault. If the resulting difference $i_{\mathrm{dc} \_ \text {diff }}$ exceeds the threshold $i_{\mathrm{dc} \_ \text {diff_th }}, f_{\mathrm{i} \_\mathrm{DC} \_ \text {diff }}$ is indicated.

The open phase fault detection is based on the estimation of the root-mean-square (RMS) values of the phase currents. Because traditional computation on blocks of data is not suitable for signal processing, the RMS computation algorithm with first-order low-pass filter was used, see Fig. 3. Neighbor RMS currents are subtracted and the maximal result is stored in $i_{\text {RMS_diff. }}$ Open phase fault $f_{\text {open_phase }}$ is detected if the $i_{\text {RMS_diff }}$ value exceeds the threshold $i_{\text {RMS_diff_th }}$.

All filters for current sensor FD uses time constant $\tau_{\mathrm{f}}=$ $100 \mathrm{~ms}$ and Euler approximation for integration.

\section{B. Position sensor FD}

Rotor position measurement is also needed for almost all algorithms in the PMSM inverter. Position sensor functionality can be verified by comparing the measured rotor angle to the estimated one. Estimator based on processing of the extended electromotive force (EEMF) voltage is used. The concept of EEMF was described in [13]. The algorithm of the estimator can be divided into two parts as depicted in Fig. 4.

The EEMF_observer block estimates EEMF voltages $e_{\alpha}$ and $e_{\beta}$ using salient PMSM model in $\alpha \beta$ coordinates

$$
\begin{aligned}
& u_{\alpha}=R_{\mathrm{S}} i_{\alpha}+L_{\mathrm{d}} \frac{\mathrm{d} i_{\alpha}}{\mathrm{d} t}+\omega\left(L_{\mathrm{d}}-L_{\mathrm{q}}\right) i_{\beta}+e_{\alpha} \\
& u_{\beta}=R_{\mathrm{S}} i_{\beta}+L_{\mathrm{d}} \frac{\mathrm{d} i_{\beta}}{\mathrm{d} t}-\omega\left(L_{\mathrm{d}}-L_{\mathrm{q}}\right) i_{\alpha}+e_{\beta},
\end{aligned}
$$




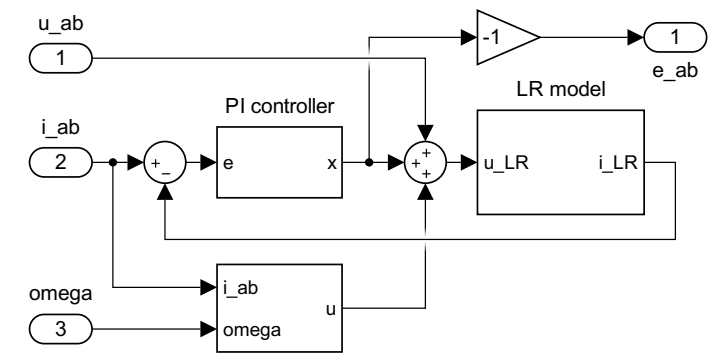

Fig. 5. The estimation block of the EEMF signals

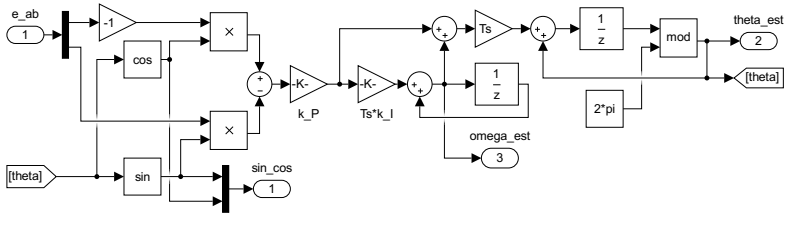

Fig. 6. The angle tracking loop structure

where $u_{\alpha}$ and $u_{\beta}$ are stator voltages in $\alpha \beta$ stationary frame, $i_{\alpha}$ and $i_{\beta}$ are respective stator currents.

Equation (21) defines $e_{\alpha}$ and $e_{\beta}$ to fulfill (19) and (20) [13].

$$
\left[\begin{array}{l}
e_{\alpha} \\
e_{\beta}
\end{array}\right]=\left[\left(L_{\mathrm{d}}-L_{\mathrm{q}}\right)\left(\omega i_{\mathrm{d}}-\dot{i_{\mathrm{q}}}\right)+\omega \Psi_{\mathrm{m}}\right]\left[\begin{array}{c}
-\sin \theta \\
\cos \theta
\end{array}\right]
$$

In steady-state the expression $\left(L_{\mathrm{d}}-L_{\mathrm{q}}\right)\left(\omega i_{\mathrm{d}}-\dot{i_{\mathrm{q}}}\right)$ is zero, therefore it is possible to estimate rotor angle from $e_{\alpha}$ and $e_{\beta}$.

The structure of the EEMF observer is in Fig. 5. The PI controllers were designed to control the LR circuit model of the motor winding. The phase margin of these controllers is $50^{\circ}$. Outputs of controllers are estimated negative EEMF voltages.

The Angle_tracking_loop block estimates rotor position and speed by angle tracking structure considering equation

$$
\sin \left(\theta_{\mathrm{EEMF}}-\hat{\theta}\right)=e_{\alpha} \cos \hat{\theta}-e_{\beta} \sin \hat{\theta} \approx \theta_{\mathrm{EEMF}}-\hat{\theta} .
$$

Where $\hat{\theta}$ is estimated rotor angle, $\theta_{\mathrm{EEMF}}$ is the angle of the EEMF $e_{\alpha}$ and $e_{\beta}$. The structure of the angle tracking loop is in Fig. 6. It should be noted, that if the rotor speed is negative, the estimated angle is $\hat{\theta}$ is $\pi \mathrm{rad}$ forward the real one [14]. This fact should be considered in the diagnostic algorithm.

The algorithm requires stator current measurement and expected stator voltages. The main advantage of this rotor position estimation algorithm is the low sensitivity to the $u_{\alpha}$ and $u_{\beta}$ amplitude error. It should be noted, that the system for estimation of the rotor angle is observable only if the rotor is spinning $\omega \neq 0[15]$.

\section{DC-bus voltage sensor FD}

The DC-bus voltage measurement $u_{\mathrm{DC}}$ is used within the FOC control algorithm to compute the phase PWM duty cycles according to required phase voltages. At first, converted $u_{\mathrm{DC}}$ value is checked to be out of the usable range, otherwise, the converted value is checked against the motor model. The DCbus voltage sensor is verified by estimation of the parameter $k_{\mathrm{dc}}$ which represents a multiplicative error of $u_{\mathrm{dq}}$ voltages. During normal operation $k_{\mathrm{dc}}=1$. The $q$-current state equation of the stator winding model modified with $k_{\mathrm{dc}}$ is used for $k_{\mathrm{dc}}$ computation.

$$
\frac{\mathrm{d} i_{\mathrm{q}}}{\mathrm{d} t}=\frac{k_{\mathrm{dc}} u_{\mathrm{q}}}{L_{\mathrm{q}}}-\frac{R_{\mathrm{s}} i_{\mathrm{q}}}{L_{\mathrm{q}}}-\frac{\omega L_{\mathrm{d}} i_{\mathrm{d}}}{L_{\mathrm{q}}}-\frac{\omega \Psi_{\mathrm{m}}}{L_{\mathrm{q}}}
$$

Considering the time derivative $\dot{i}_{\mathrm{q}}$ is considerably low within the sampling period, we can rewrite (23) and compute $k_{\mathrm{dc}}$ directly

$$
k_{\mathrm{dc}} u_{\mathrm{q}}=R_{\mathrm{s}} i_{\mathrm{q}}+\omega L_{\mathrm{d}} i_{\mathrm{d}}+\omega \Psi_{\mathrm{m}} .
$$

It is obvious, that computation of $k_{\mathrm{dc}}$ is defined only if $u_{\mathrm{q}} \neq 0$. Practically, the computation is only made if $\left|u_{\mathrm{q}}\right|>u_{\mathrm{q}_{-} \mathrm{th}}$. The output of the $k_{\mathrm{dc}}$ computation is filtered by a first-order lowpass with time constant $\tau_{\mathrm{DC}}=50 \mathrm{~ms}$ before further usage. Simulink realization of the $k_{\mathrm{dc}}$ computation is in Fig. 7.

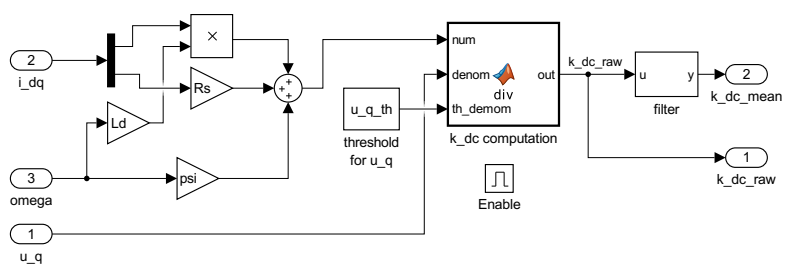

Fig. 7. Diagram of the $k_{\mathrm{dc}}$ estimation block

The algorithm requires the correct measurement of the phase currents and rotor position. If the inequalities $\left|k_{\mathrm{dc}}-1\right|>k_{\mathrm{dc} \_ \text {th }}$ and $\left|u_{\mathrm{q}}\right|>u_{\mathrm{q}_{-} t \mathrm{t}}$ are fulfilled and the position sensor and phase current sensors outputs are valid, the DC-bus voltage sensor is considered faulty, what is indicated by $f_{\mathrm{u}_{-} \mathrm{DC}}$ signal.

\section{Diagnostic ALGORITHM}

The diagnostic algorithm of the winding and sensor faults is described by the flowchart in Fig. 8. It uses outputs of previously mentioned FD algorithms and prioritizes their outputs to recognize the most important fault.

\section{IMPLEMENTATION}

During all tests, the industrial PMSM servomotor was used (Fig. 1). Its parameters are in Table II. The motor has two winding steps, which can shorten a portion of winding denoted as $\sigma$ by fault resistance $R_{\mathrm{f}}$. The VUES ASD 2000-2-40 dynamometer in the speed control model was used as a motor load. The PMSM inverter controls the torque of the motor, emulated fault, and provides reference speed of dynamometer. The dynamometer is controlled over RS-485 MODBUS. The diagram of the whole system is in Fig. 9.

The inverter is divided into two boards, the 3-phase low voltage inverter [16] and the STM32F4DISCOVERY development board. The STM32F407VGT6 ARM Cortex M4F microcontroller clocked at $192 \mathrm{MHz}$ is the central point of the inverter. The configuration of the control system ensures 


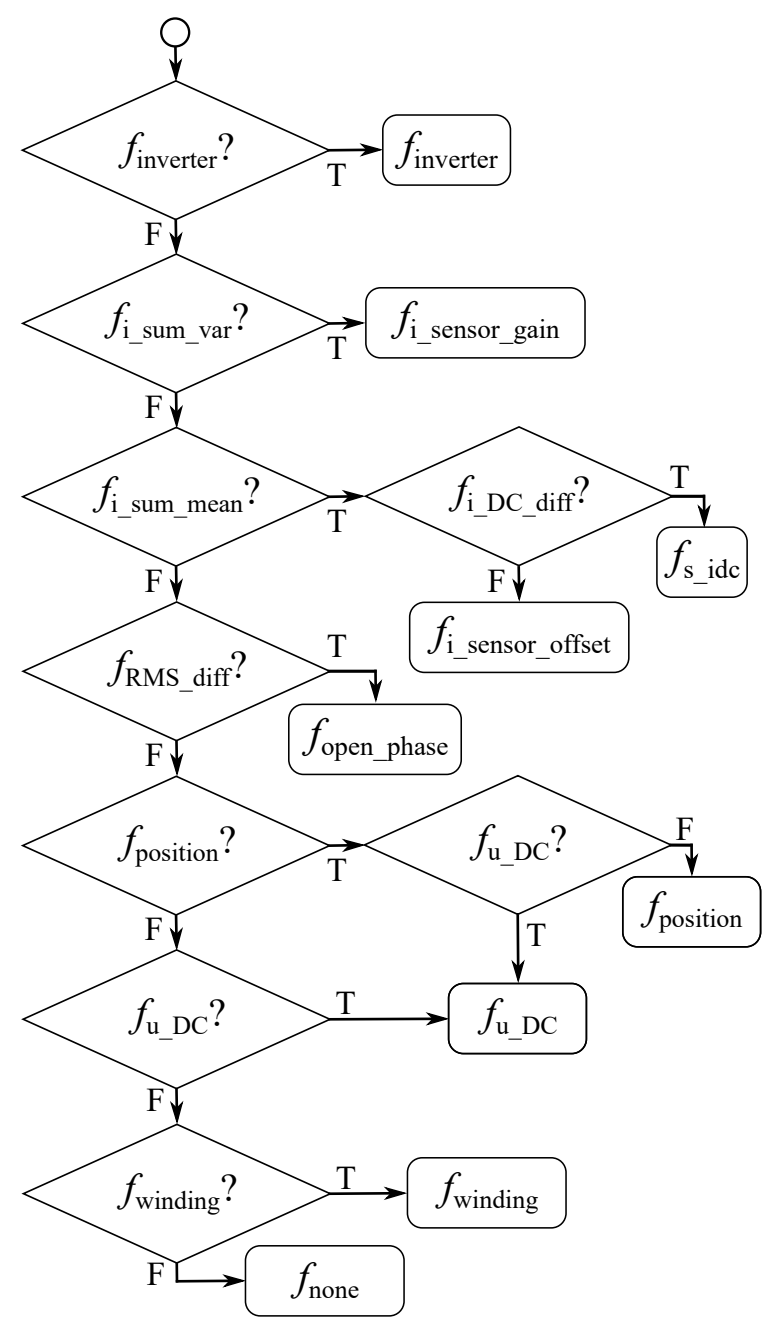

Fig. 8. Flowchart of the $f_{\mathrm{DET}}$ diagnostic system of the winding and sensor faults

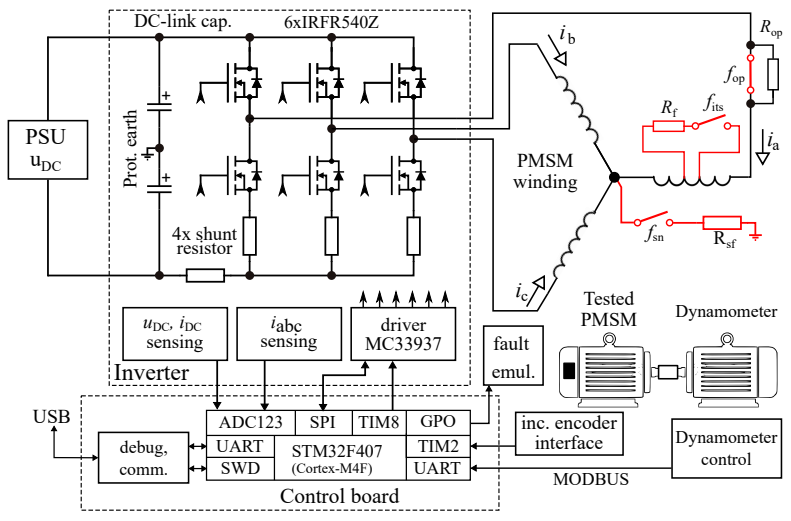

Fig. 9. Block diagram of the considered inverter realization with HW emulated faults (in red color)

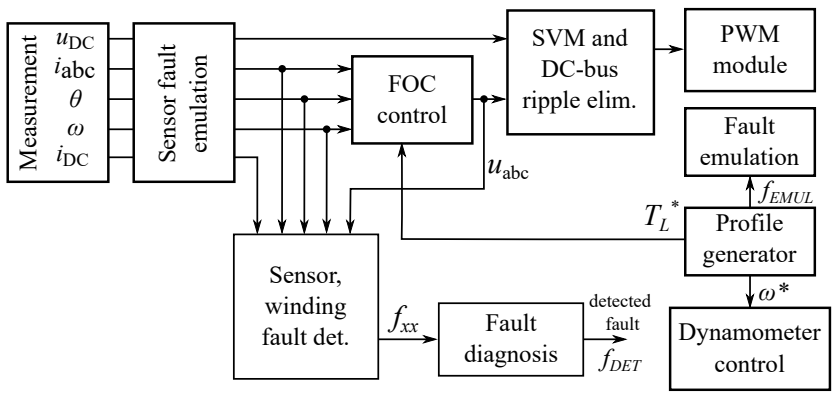

Fig. 10. Block diagram of the inverter SW

TABLE II

THE PMSM PARAMETERS (TG DRIVES TGT3-0130-15-36/T4KX)

\begin{tabular}{|l|c|l|}
\hline Parameter & Symbol & Value \\
\hline \hline Nominal torque & $T_{\mathrm{n}}$ & $1.25 \mathrm{~N} \mathrm{~m}$ \\
\hline Nominal velocity & $\omega_{\mathrm{n}}$ & $157 \mathrm{rad} \mathrm{s}^{-1}$ \\
\hline Nominal current & $I_{\mathrm{n}}$ & $8.55 \mathrm{~A}$ \\
\hline Rotor inertia & $J$ & $0.65 \times 10^{-4} \mathrm{~kg} \mathrm{~m}^{2}$ \\
\hline Pole pairs & $P_{\mathrm{P}}$ & 3 \\
\hline Rotor permanent magnet flux & $\Psi_{\mathrm{m}}$ & $0.025 \mathrm{~V} \mathrm{~s}$ \\
\hline Stator resistance & $R_{\mathrm{s}}$ & $0.323 \Omega$ \\
\hline Direct inductance & $L_{\mathrm{d}}$ & $440 \mu \mathrm{H}$ \\
\hline Quadrature inductance & $L_{\mathrm{q}}$ & $564 \mu \mathrm{H}$ \\
\hline Zero-sequence inductance & $L_{0}$ & $410 \mu \mathrm{H}$ \\
\hline Stator inter-turn short severity & $\sigma$ & $9 / 60$ \\
\hline Emulated inter-turn short resistance & $R_{\mathrm{f}}$ & $80 \mathrm{~m} \Omega$ \\
\hline Emulated open phase resistance & $R_{\mathrm{op}}$ & $33 \Omega$ \\
\hline Emulated star-to-earth resistance & $R_{\mathrm{sf}}$ & $12 \Omega$ \\
\hline
\end{tabular}

$16 \mathrm{kHz}$ sampling rates for the motor control loop and fault detection algorithm. A 6 MBaud serial communication link is used for the real-time recording of the inverter signals. All currents are sensed on $15 \mathrm{~m} \Omega$ shunt resistors by voltage measurement and its amplification before 12-bit AD conv ersion. The DC bus voltage is sensed by resistor divider and 12-bit ADC. Rotor position is sensed by the incremental encoder with 4096 edges per mechanical revolution.

Firmware of the microcontroller consists of Simulink generated code and low-level drivers. Its structure is in Fig. 10. The control algorithm is running at $16 \mathrm{kHz}$. Deadtime of MOSFET power devices is $100 \mathrm{~ns}$.

\section{A. Experimental results}

Presented algorithms were implemented in Matlab/Simulink environment and tested on recorded signals from real PMSM motor connected to the inverter. These signals were recorded with different HW and SW emulated faults activated within control loop. In all experiments, all presented FD methods are running and the $f_{\mathrm{DET}}$ fault is diagnosed according to Fig. 8.

The operating point of the PMSM during all experiments was defined by the profile of rotor mechanical speed reference $\omega_{\mathrm{m}}^{*}$ and load torque reference $T_{\mathrm{L}}^{*}$, see Fig. 11. Totally 25 operating points were selected including $\omega_{\mathrm{m}}^{*} \in\left\{300 \mathrm{~min}^{-1}\right.$, $600 \mathrm{~min}^{-1}, 900 \mathrm{~min}^{-1}, 1200 \mathrm{~min}^{-1}$ and $\left.1500 \mathrm{~min}^{-1}\right\}$ and $T_{\mathrm{L}}^{*} \in\{0 \mathrm{Nm}, 0.3 \mathrm{Nm}, 0.6 \mathrm{Nm}, 0.9 \mathrm{Nm}$ and $1.2 \mathrm{Nm}\}$ to 

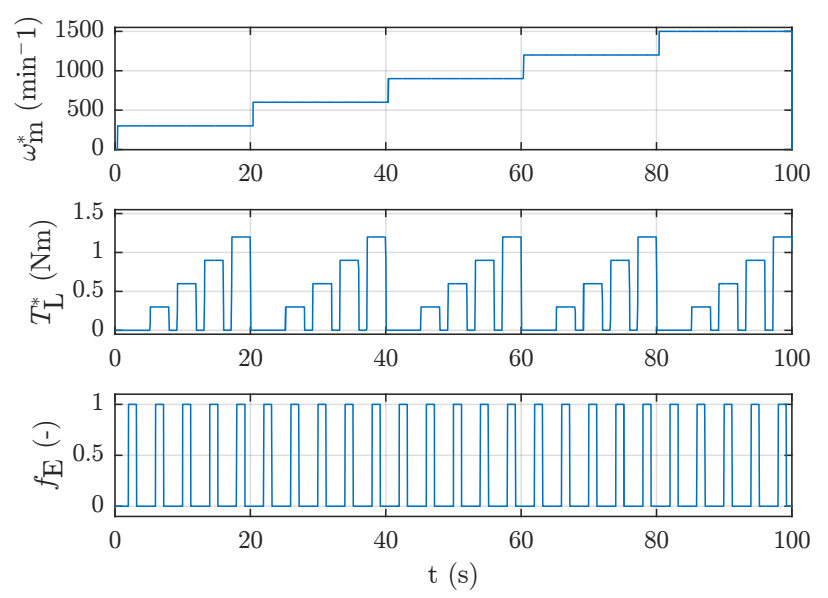

Fig. 11. Rotor mechanical speed, load torque, fault emulation profiles

TABLE III

FD THRESHOLD SETTINGS USED IN EXPERIMENTS

\begin{tabular}{|l|c|l|}
\hline Parameter & Symbol & Value \\
\hline \hline Phase currents RMS difference threshold & $i_{\text {RMS_diff_th }}$ & $0.6 \mathrm{~A}$ \\
\hline Phase currents sum mean threshold & $i_{\text {sum_mean_th }}$ & $0.5 \mathrm{~A}$ \\
\hline Phase currents sum variance threshold & $i_{\text {sum_var_th }}$ & $0.5 \mathrm{~A}$ \\
\hline DC-bus current measurement diff. threshold & $i_{\text {dc_diff_th }}$ & $0.1 \mathrm{~A}$ \\
\hline DC-bus voltage sensor fault threshold & $k_{\text {dc_th }}$ & 0.1 \\
\hline Position sensor angle fault threshold & $\theta_{\text {diff_th }}$ & 15 \\
\hline Winding inter-turn short fault threshold & $\delta_{\text {mm_th }}$ & 0.02 \\
\hline
\end{tabular}

cover a whole nominal operating range of used motor (see Table II). Each experiment is $100 \mathrm{~s}$ long. During the steadystate of each operating point, the particular fault was abruptly activated according to $f_{\mathrm{E}}$ profile. The detection algorithms were used with parameters summarized in Table III.

\section{B. Winding related faults}

The winding inter-turn short fault experiment signals are in Fig. 12. The $15 \%$ of the winding was shorted by electromechanical relay. The third graph in all experiments shows the output of the diagnostic algorithm $f_{\mathrm{DET}}$. As you may notice the algorithm correctly detect all emulated faults. Moreover, the amplitude of the $\delta_{\mathrm{mm}}$ is almost constant within the operating range.

Open phase fault experiment signals are in Fig. 13. During the open phase experiment, $R_{\mathrm{op}}$ resistor was inserted into phase leg. If the motor was loaded, the fault was detected. Because the RMS computation dynamic is relatively slow, we can observe short peaks in diagnosed fault.

Signals of the winding star-point short to the motor case (current leakage) experiment are in Fig. 14. We can observe that fault was detected during all operating point. But $i_{\text {DC_est }}$ must be well compensated by $k_{\text {gain }}$ and $k_{\text {bias }}$.

\section{Sensor faults}

The phase current gain sensor fault experiment signals are in Fig. 15. Because the error signal $i_{\text {sum_var }}$ is proportional to load torque, it is not possible to detect this kind of sensor
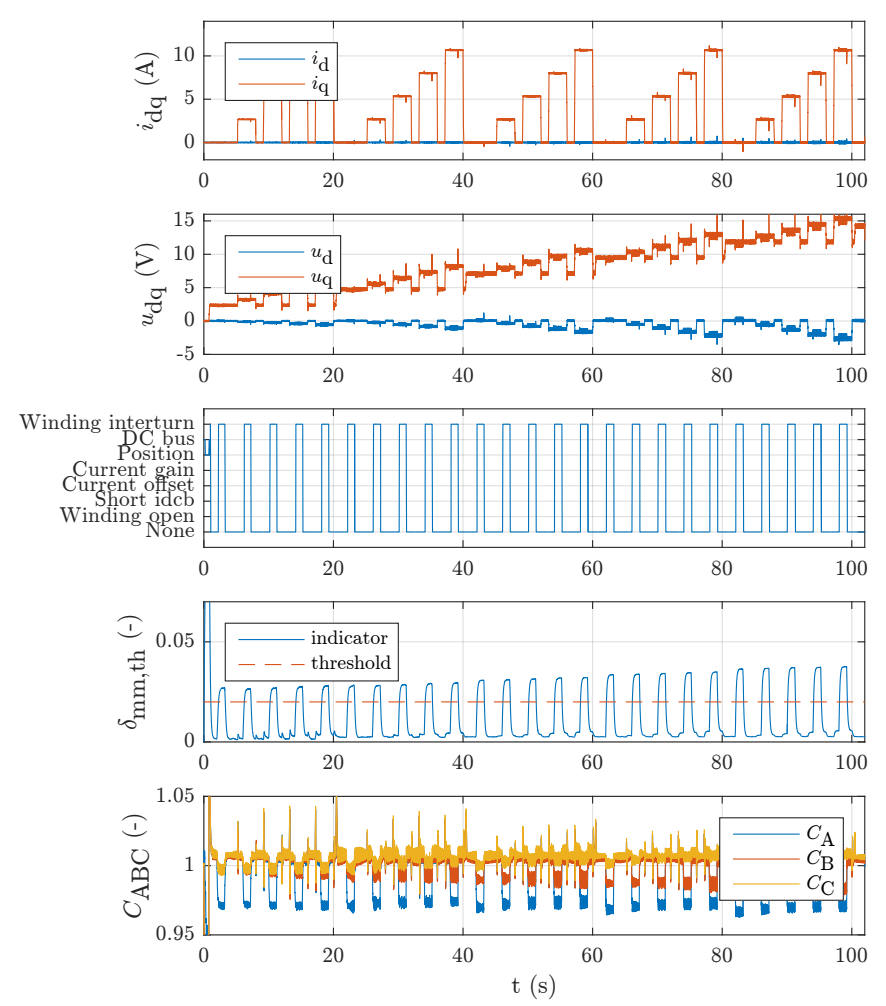

Fig. 12. Inter-turn short experiment, $15 \%$ of a phase winding shorted $R_{\mathrm{f}}=$ $64 \mathrm{~m} \Omega$
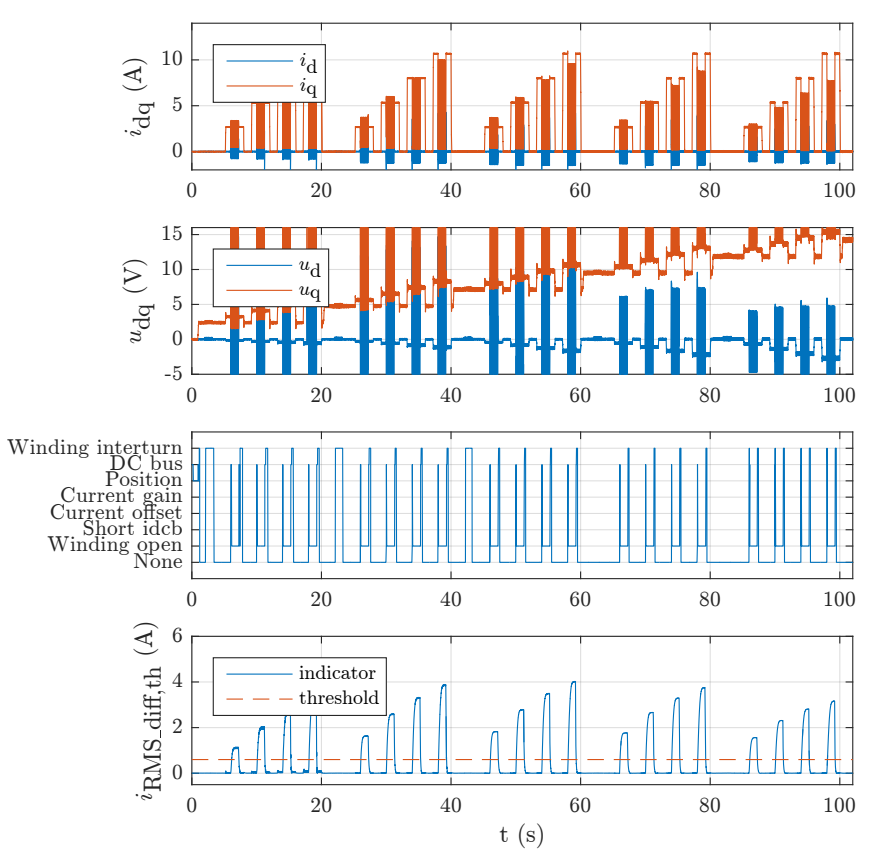

Fig. 13. Winding open-phase experiment with $R_{\mathrm{op}}=33 \Omega$

fault at low loads. Therefore there are parts when the gain error fault is diagnosed by winding fault algorithm instead of sensor fault algorithm. With loaded motor the current sensor 

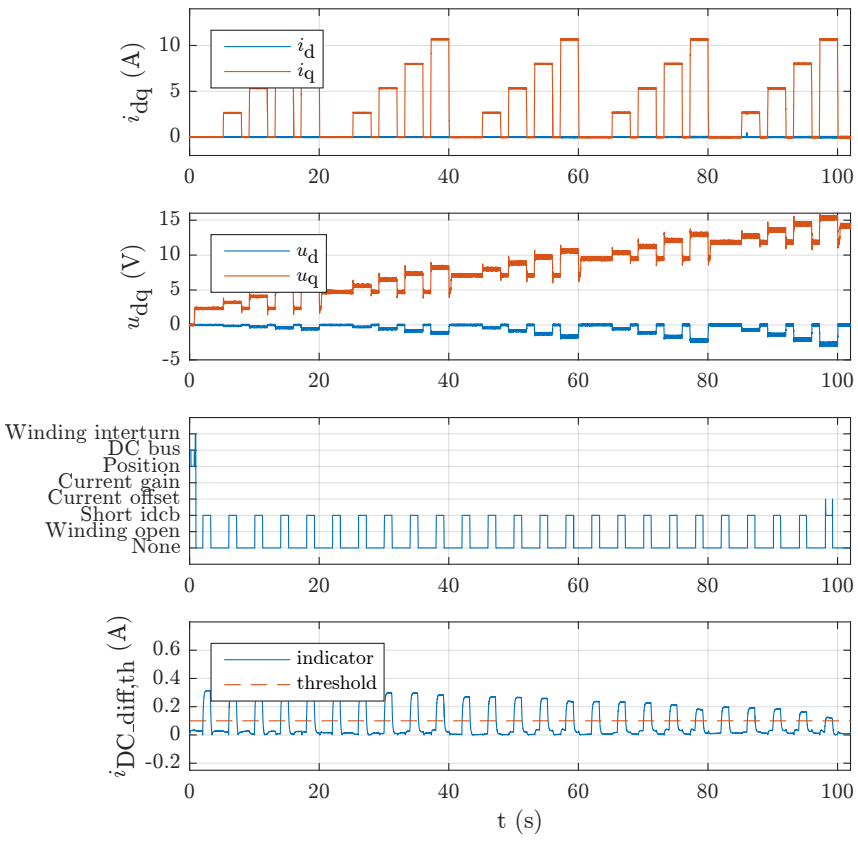

Fig. 14. Winding star-point to motor case short (current leakage) fault with resistor $R_{\mathrm{sf}}=12 \Omega$

gain error is detected correctly.
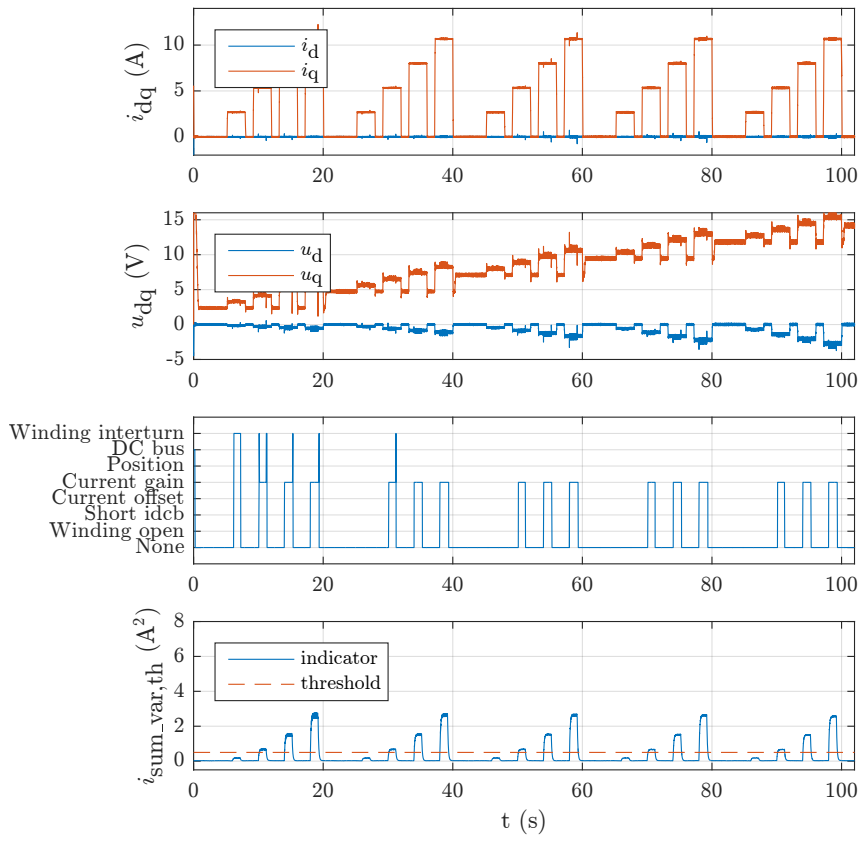

Fig. 15. Phase current sensor 0.8 gain error experiment

The phase current offset error experiment signals are in Fig. 16. In all situations, the sensor offset fault is correctly diagnosed during a steady-state. But in during transitions also $i_{\text {sum_var }}$ signal is incorrect due to simple implementation of mean/variance estimation algorithm.
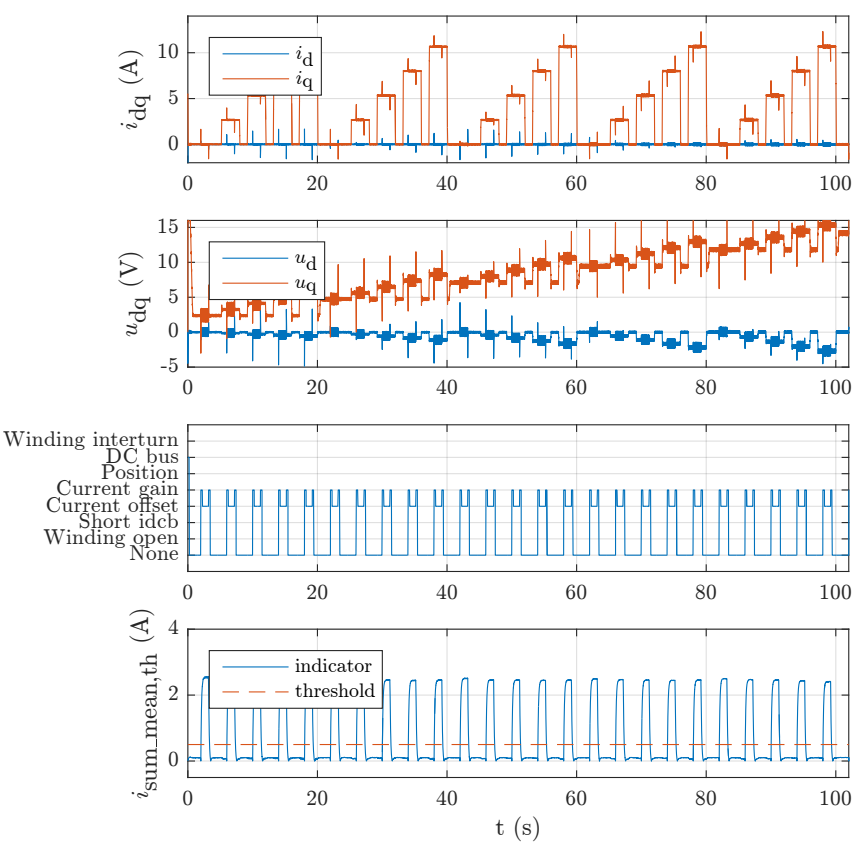

Fig. 16. Phase current sensor $2.5 \mathrm{~A}$ offset experiment

The DC-bus voltage sensor fault experiment signals are in Fig. 17. During the experiment, the gain of DC-bus voltage sensor was artificially reduced to 0.8 . The experiment shows that the DC-bus sensor fault was detected within the whole operating range.
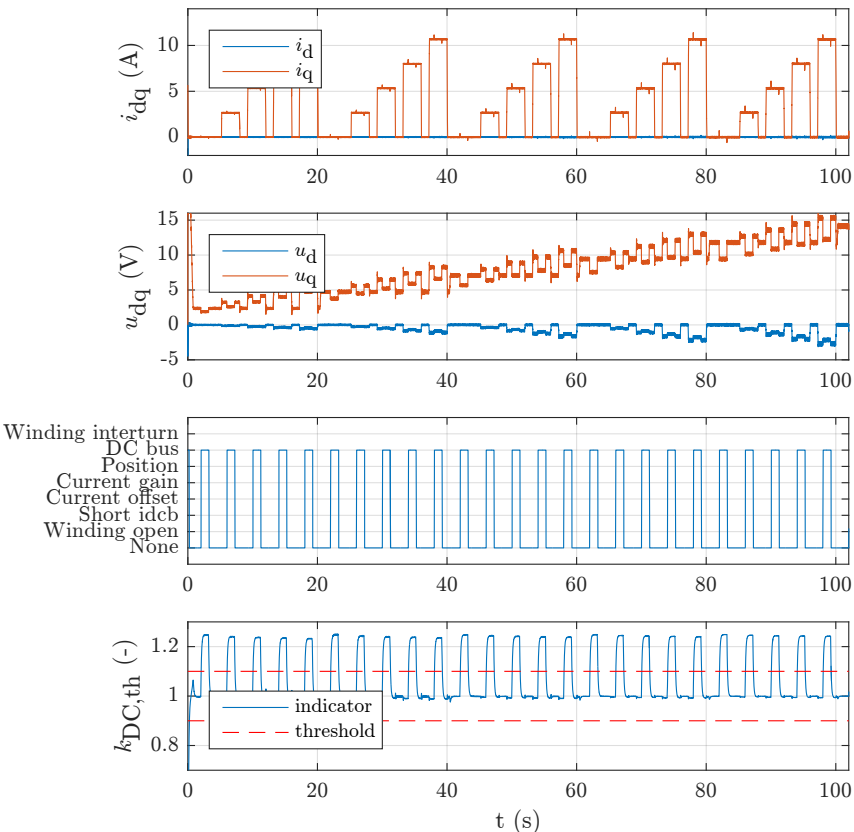

Fig. 17. DC-bus voltage sensor 0.8 gain fault experiment

Signals of the position sensor fault experiment are in Fig. 18. The position error of $20^{\circ}$ was emulated in SW within 
motor control loop. This can be a situation of the misaligned position sensor. It can be seen, that EEMF based rotor position estimation algorithm can track rotor position with only small error, and the fault is diagnosed in all of the cases within the whole operating range.
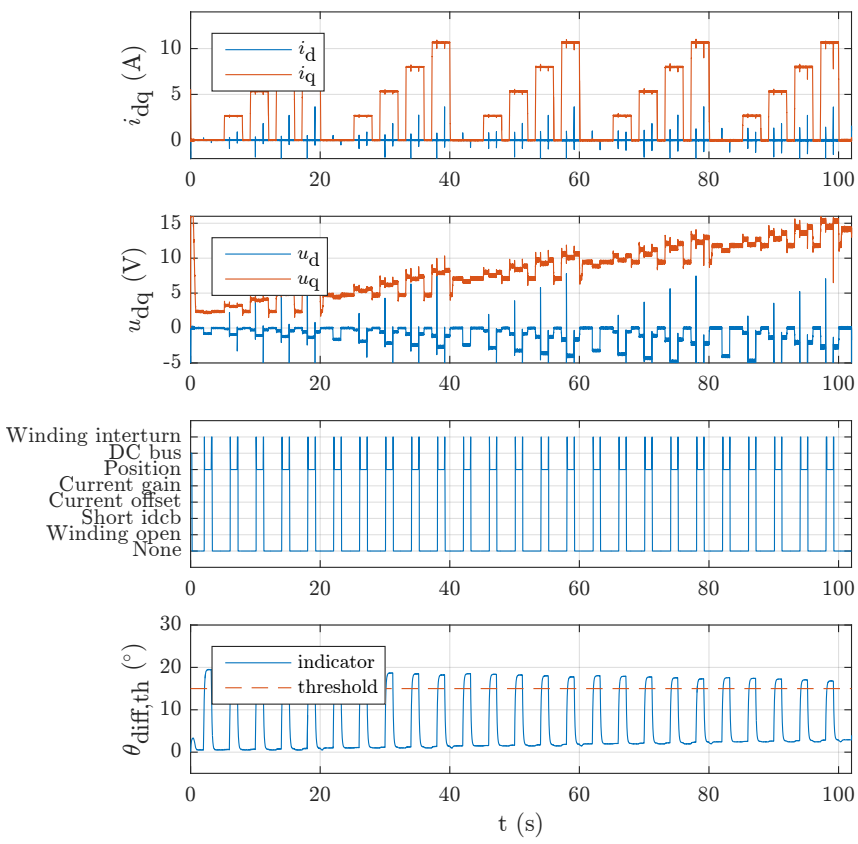

Fig. 18. The position sensor $20^{\circ}$ absolute error experiment

It can be commonly seen in experiments, that the transition band of the detected fault is not clear, therefore the glitch filter should be used on the output of the fault diagnostic algorithm.

\section{CONCLUSION}

This paper described possibilities of detection winding faults of the PMSM motor together with verification of sensor functionality with only a limited number of additional sensors. The HW of the industrial PMSM testbench was described with the reasoning of the used sensors and fault emulation schemes.

Experimental results of FD algorithms show the $f_{\text {DET }}$ response on the HW/SW emulated faults, which only slightly influence control of the PMSM but which can transform into more serious faults. The performance of the winding inter-turn FD algorithm based on EKF is very reliable and consistent within the whole operating range. Sensor FD algorithms support the winding FD algorithm because it needs correct and precise sensor signals for its operation.

Presented experimental results were computed inside Matlab/Simulink environment with data measured on real PMSM drive and the algorithms were also successfully tested on the control microcontroller. It was verified that it is possible to run both, the winding fault detection algorithm and the sensor fault detection algorithm (Simulink generated code) together with FOC on the microcontroller. Measured computational time was $40.57 \mu$ s maximally for the winding FD algorithm and $7.85 \mu \mathrm{s}$ for the sensor FD algorithm.

\section{REFERENCES}

[1] Y. Da, X. Shi, and M. Krishnamurthy, "Health monitoring, fault diagnosis and failure prognosis techniques for Brushless Permanent Magnet Machines," in 2011 IEEE Vehicle Power and Propulsion Conference. IEEE, Sep. 2011, pp. 1-7.

[2] R. Hu, J. Wang, A. Mills, E. Chong, and Z. Sun, "Current Residual Based Stator Inter-Turn Fault Detection in Permanent Magnet Machines," IEEE Transactions on Industrial Electronics, pp. 1-1, 2020. [Online]. Available: https://ieeexplore.ieee.org/document/8960656/

[3] M. A. Mazzoletti, G. R. Bossio, C. H. De Angelo, and D. R. EspinozaTrejo, "A Model-Based Strategy for Interturn Short-Circuit Fault Diagnosis in PMSM," IEEE Transactions on Industrial Electronics, vol. 64, no. 9, pp. 7218-7228, Sep. 2017. [Online]. Available: http://ieeexplore.ieee.org/document/7889000/

[4] R. Mocanu and A. Onea, "Phase resistance estimation and monitoring of PMSM used in electrical vehicles," in 2014 18th International Conference on System Theory, Control and Computing (ICSTCC). IEEE, Oct. 2014, pp. 512-519. [Online]. Available: http://ieeexplore.ieee.org/lpdocs/epic03/wrapper.htm?arnumber=6982468

[5] B. Aubert, J. Regnier, S. Caux, and D. Alejo, "Stator inter-turn short-circuit detection in permanent magnet synchronous generators using extended Kalman filtering," in 2013 IEEE 11th International Workshop of Electronics, Control, Measurement, Signals and their application to Mechatronics. IEEE, Jun. 2013, pp. 1-6. [Online]. Available: http://ieeexplore.ieee.org/document/6648943/

[6] S.-G. Ahn, B.-G. Park, R.-Y. Kim, and D.-S. Hyun, "Fault diagnosis for open-phase faults of permanent magnet synchronous motor drives using Extended Kalman Filter," in IECON 2010 - 36th Annual Conference on IEEE Industrial Electronics Society. IEEE, Nov. 2010, pp. 835-840. [Online]. Available: http://ieeexplore.iee.org/lpdocs/epic03/wrapper.htm?arnumber=5675176

[7] G. F. H. Beng, X. Zhang, and D. M. Vilathgamuwa, "Sensor Fault-Resilient Control of Interior Permanent-Magnet Synchronous Motor Drives," IEEE/ASME Transactions on Mechatronics, vol. 20, no. 2, pp. 855-864, Apr. 2015. [Online]. Available: $\mathrm{http} / / /$ ieeexplore.iee.org/document/6784125/

[8] G. H. B. Foo, X. Zhang, and D. M. Vilathgamuwa, "A Sensor Fault Detection and Isolation Method in Interior PermanentMagnet Synchronous Motor Drives Based on an Extended Kalman Filter," IEEE Transactions on Industrial Electronics, vol. 60, no. 8, pp. 3485-3495, Aug. 2013. [Online]. Available: http://ieeexplore.ieee.org/document/6428675/

[9] L. Otava and L. Buchta, "Implementation and verification of the PMSM stator interturn short fault detection algorithm," in 2017 19th European Conference on Power Electronics and Applications (EPE'17 ECCE Europe). IEEE, Sep. 2017, pp. P.1-P.10. [Online]. Available: https://ieeexplore.ieee.org/document/8099080

[10] S. E. Lyshevski, Electromechanical Systems, Electric Machines, and Applied Mechatronics, ser. Electric Power Engineering Series. Taylor \& Francis, 1999. [Online]. Available: http://books.google.cz/books?id=3GYU1N1XKw8C

[11] P. P. Kundur, N. J. Balu, and M. G. Lauby, Power system stability and control. McGraw-Hill, 1994.

[12] G. Welch and G. Bishop, "An Introduction to the Kalman Filter," In Practice, vol. 7, no. 1, pp. 1-16, 2006.

[13] Zhiqian Chen, M. Tomita, S. Doki, and S. Okuma, "An adaptive sliding observer for sensorless control of synchronous motors," in Proceedings of the 2001 IEEE International Conference on Control Applications (CCA'01) (Cat. No.01CH37204). IEEE, 2001, pp. 738-743. [Online]. Available: http://ieeexplore.iee.org/document/973956/

[14] R. Filka, P. Balazovic, and B. Dobrucky, "A Seamless Whole Speed Range Control of Interior PM Synchronous Machine without Position Transducer," in 2006 12th International Power Electronics and Motion Control Conference. IEEE, Aug. 2006, pp. 1008-1014. [Online]. Available: http://ieeexplore.ieee.org/document/4778532/

[15] P. Vaclavek and P. Blaha, "Synchronous machine drive observability analysis and sensorless control design," in 2008 IEEE 2nd International Power and Energy Conference, no. PECon 08. IEEE, Dec. 2008, pp. 265-270. [Online]. Available: http://ieeexplore.ieee.org/lpdocs/epic03/wrapper.htm?arnumber=4762482

[16] Freescale, "3-Phase BLDC / PMSM Low Voltage Power Stage User Guide," 2012. 